\title{
An Overview of Carbon Offsets from Agriculture
}

\author{
Jimena González-Ramírez ${ }^{1}$, Catherine L. Kling ${ }^{2}$, Adriana Valcu ${ }^{3}$
}

This research is part of a regional collaborative project supported by the USDA-NIFA, Award No. 2011-68002-30190, "Cropping Systems Coordinated Agricultural Project (CAP): Climate Change, Mitigation, and Adaptation in Corn-based Cropping Systems." The authors also appreciate support from a Cooperative Agreement with USDA, Economic Research Service "The supply of greenhouse gas offsets from agriculture and their water quality effects in the Upper Mississippi River Basin."

Keywords: GHGs, carbon policy, conservation practices, carbon supply curves, additionality, leakage.

\begin{abstract}
While climate change has largely been removed from the federal policy agenda of the United States in the near term, the continued reliance on fossil fuels as a dominant energy source leaves many analysts to conclude that climate policy will eventually reappear on that agenda. We present a review of recent research related to the design and implementation of one instrument for greenhouse gas (GHG) reduction: offsets. As these are implemented, policy makers must understand the way these programs work. In this review, we describe the basic features of carbon offset markets, along with the potential supply of offsets from agricultural sources and associated cost considerations. In this discussion we highlight the role of institutional design of contracts and transactions costs. We then turn to the benefits of including offsets in policies to reduce GHGs and complete the review with a discussion of the challenges in implementing the programs.
\end{abstract}

\section{Introduction}

\footnotetext{
${ }^{1}$ Graduate Research Assistant, Department of Economics, lowa State University; email: majimena@iastate.edu

${ }^{2}$ Professor of economics at lowa State University and head of the Resource and Environmental Policy Division at CARD; email: ckling@iastate.edu

${ }^{3}$ Graduate Research Assistant, Department of Economics, Iowa State University; email: amvalcu@iastate.edu
} 
While climate change has largely been removed from the federal policy agenda of the United States in the near term, the continued reliance on fossil fuels as a dominant energy source leaves many analysts to conclude that climate policy will eventually reappear on that agenda. This hiatus from immediate policy discussion provides a window for researchers to evaluate the set of instruments that have been considered in these programs. In this paper, we present a review of recent research related to the design and implementation of one instrument for greenhouse gas (GHG) reduction that has been the source of much controversy in the development of regulations: offsets. While many types of offsets have been considered, we focus our discussion on agricultural offsets from domestic sources. In addition to providing a set of relatively comparable offsets in which to compare findings, the offset potential of agriculture in the U.S. is likely to be a major focus on the next farm bill and related conservation programs. While not necessarily framed as "offsets," the agricultural practices and land use changes that can reduce atmospheric GHGs can be addressed by other types of policy such as green payments and subsidies. Thus, much of the literature related to agricultural offsets is equally relevant to the design of conservation programs and U.S. farm policy.

Making this review and evaluation even more salient is the fact that climate policy is increasingly being taken up by states where many of the same instruments are being adopted and/or considered. Notably, in October of 2011, California completed its regulations to adopt a cap and trade program (http://arb.ca.gov/cc/capandtrade/capandtrade.htm). Of particular interest is the fact that the California program has an explicit offset program which will allow emission reductions from uncapped sectors to be purchased by capped industries thereby meeting their reduction requirements (http://www.arb.ca.gov/cc/capandtrade/meetings/062210/offset program update.pdf). Specifically, though the California offset program is initially focused on forest offsets, ozone depleting substances, and livestock, the legislation allows for the possibility of additional sources of offsets over time. 
Of course, carbon offset programs have been incorporated into the design of GHG mitigation policies in the international arena. Notably, the Clean Development Mechanism (CDM) in the Kyoto Protocol has received considerable attention (Bushnell 2010; Lecocq \& Ambrosi 2007 ) and proposed climate change policies in the United States included carbon sequestration from agricultural practices as potential offsets (such as H.R. 2454). A number of offsets have been promulgated under the CDM. In particular, the CDM could potentially achieve an estimate of 3,000 $\mathrm{MtCO}_{2 \mathrm{e}}$ savings projected to 2012 according to project design documents (Grubb et al. 2011). These carbon sequestration policies have been criticized for a variety of reasons including the high information costs required to measure their benefits at specific sites and the existence of information asymmetries between government and farmers (Antle et al. 2003), although he also notes that incentive based regulations, such as offsets, are more efficient than command-and-control regulations due to the variability of mitigation costs across sources (Antle, 2008). These points suggest that there is ample room for researchers to explore more efficient ways to design carbon offset programs. Finally, as these programs are implemented, policy makers must understand the way agricultural carbon offset programs work, their benefits, and some of the challenges that will be faced in their design.

In the remainder of this review, we begin by describing the basic features of carbon offset markets, along with the potential supply of offsets from agricultural sources and associated cost considerations. In this discussion we highlight the role of institutional design of contracts and transactions costs rather than the biological and physical aspects. For a very clear biological description of the process of carbon sequestration in soils and forests, refer to "Carbon Sequestration in Forests and Soils" by Sedjo and Sohngen in this volume. In addition to discussing issues related to carbon sequestration by forests and soils, they also provided a detailed explanation of the processes through which conservation practices increase soil and forest carbon sequestration (Sedjo and Sohngen 2012). Towards the end of this review, 
we turn to the benefits of including offsets in policies to reduce GHGs and complete the review with a discussion of the challenges in implementing the programs.

\section{GHG offset programs in agriculture}

As noted earlier, offsets are simply a way in which sources of emission reductions outside the capped sector can participate in a cap-and-trade program for an environmental good. Thus, in the California system for example, the capped sector covers about $85 \%$ of the GHG generating and brings additional sources under the cap over time. Sometimes the terminology "baseline-and-trade" is used to differentiate programs that provide credits to firms that reduce emissions below a baseline level. These reductions below the baseline are equivalent to an offset, which can then be sold to emission sources that exceed their baseline.

Offset programs may exist for many reasons including the fact that traditional regulatory measures are constrained by jurisdiction and practicality (Bushnell 2010). They will be desirable for implementation when reductions to these outside sources can be achieved less expensively than reductions to the covered sources, thereby decreasing the costs of program compliance. For example, conservation practices that increase the storage of carbon in agricultural soils may be a less expensive way to keep carbon out of the atmosphere than activities from the capped sectors. There are a wide variety of agricultural practices and land management changes in agriculture that have been identified as potential sources of GHG reductions. These include retiring land from agricultural production and replanting perennial cover (such as trees or perennial grasses), the addition of cover crops to standard cropping systems and the use of reduced tillage to increase the amount of soil organic matter and carbon sequestration in the soil. In addition, grazing land management and biofuel substitution are also identified by EPA as potential options. For representative sequestration rates from those practices see www.epa.gov/sequestration/rates.html. 


\subsection{Supply Curves and Spatial Heterogeneity}

An important starting point is to determine the potential of carbon offsets from agriculture. Policy makers and analysts need to distinguish between technical potential and economic potential, in which technical potential is defined as the biophysical capacity to reduce emissions due to the different conservation practices (Gramig 2010). Moreover, technical potential does not include costs and is affected by spatial heterogeneity (Antle 2008). On the other hand, economic potential includes cost effectiveness and feasibility of conservation practices. Smith et al. (2008) illustrate the difference between the two potentials in their assessment of carbon sequestration, which includes all GHGs with breakdowns for all global regions and all gases. They estimate 2030 global technical potential to be at most between 5,500 to 6,000 MtCO2e/year. Similarly, they estimate 2030 global economic potential to be at least 1,500 McO2e/year for a carbon price of $\$ 20 / \mathrm{tCO} 2$ and at most 4,300 MtCO2e/year for a price of $\$ 100 /$ tCO2 (Smith et al. 2008). Clearly, economic potential is the appropriate measure that policy makers should consider when designing carbon offsets program.

Once policy makers understand the economic potential of carbon offsets from agriculture, supply curves are estimated to determine the amount of carbon that is sequestered given a carbon price. Supply curves are derived using the opportunity cost, which is basically the difference between the return under a current cultivation practice and the return from adopting a conservation practice. In other words, a farmer adopts a different practice if the opportunity cost per hectare that is changed to a new conservation practice is less than the payment from the offset contract (Mooney et al. 2002). For example, the opportunity of land retirement is measured by the cropland cash rental rate (Feng et al. 2005). Several authors (Aldy et al. 2009; Gramig 2010; McCarl \& Schneider 2001) agree that as the price of carbon increases, carbon offsets should originate from afforestation, since agricultural carbon 
sequestration has lower economic potential compared to afforestation. Sedjo and Sohngen provide a detailed description about carbon sequestration in forests in their review in this volume.

Antle et al. explore the way carbon supply curves are affected by spatial heterogeneity. In fact, they notice a negative relation between payment levels and spatial heterogeneity. In other words, as payment levels increase, the opportunity costs increase as well, which reduces the coefficient of variation in opportunity costs (Antle et al. 2003). As the land is more heterogeneous, relative efficiency of per hectare contracts decreases as measurement costs increase (Antle et al. 2003). They conclude that it is important to use carbon supply curves that are derived taking into account opportunity costs and spatial heterogeneity.

Supply curves for carbon offsets from agricultural practices have been estimated by a number of authors. Table 1 includes a summary of a number of recent studies which provide a range of estimates associated with various conservation practices. 
Table 1 Empirical Studies

\begin{tabular}{|c|c|c|c|c|c|}
\hline Source & Location & $\begin{array}{l}\text { Agricultural } \\
\text { commodity }\end{array}$ & Policy design & $\begin{array}{l}\text { Conservation } \\
\text { practices }\end{array}$ & $\begin{array}{l}\text { Simulation } \\
\text { Model or } \\
\text { Methodology }\end{array}$ \\
\hline $\begin{array}{l}\text { Pautsch et } \\
\text { al. } 2000\end{array}$ & lowa & $\begin{array}{l}\text { Corn, } \\
\text { soybean, } \\
\text { wheat, } \\
\text { sorghum \& } \\
\text { hay }\end{array}$ & $\begin{array}{l}\text { Single per acre } \\
\text { subsidy \& price } \\
\text { discrimination } \\
\text { subsidy }\end{array}$ & Conservation Tillage & $\begin{array}{l}\text { Logit model of } \\
\text { conservation } \\
\text { tillage adoption }\end{array}$ \\
\hline $\begin{array}{l}\text { Mooney et } \\
\text { al. } 2002\end{array}$ & Montana & Small grain & $\begin{array}{l}20 \text { year per-tonne } \\
\text { contract in which } \\
\text { areas are sampled } 4 \\
\text { times }\end{array}$ & $\begin{array}{l}\text { Spring wheat- } \\
\text { fallow, barley- } \\
\text { fallow, winter } \\
\text { wheat-fallow, grass } \\
\text { and spring wheat, } \\
\text { barley, and winter } \\
\text { wheat }\end{array}$ & Century \\
\hline $\begin{array}{l}\text { Antle et al. } \\
2003\end{array}$ & $\begin{array}{l}\text { Northern } \\
\text { Plains } \\
\text { Region } \\
\text { (USA) }\end{array}$ & $\begin{array}{l}\text { Dryland } \\
\text { production } \\
\text { systems }\end{array}$ & $\begin{array}{l}20 \text { year per-tonne } \\
\text { contract in which } \\
\text { areas are sampled } 4 \\
\text { times }\end{array}$ & Tillage practices & Century \\
\hline $\begin{array}{l}\text { Kurkalova, } \\
\text { Kling \& Zhao } \\
\text { 2004b }\end{array}$ & lowa & $\begin{array}{l}\text { Corn and } \\
\text { soybean }\end{array}$ & Green subsidies & Conservation tillage & EPIC \\
\hline $\begin{array}{l}\text { Feng et al. } \\
2005\end{array}$ & $\begin{array}{l}\text { Upper } \\
\text { Mississippi } \\
\text { River } \\
\text { Basin } \\
\text { (UMRB) }\end{array}$ & $\begin{array}{l}\text { Wheat, } \\
\text { corn, } \\
\text { soybean, } \\
\text { and cash } \\
\text { grains }\end{array}$ & $\begin{array}{l}\text { Green payment } \\
\text { type policy }\end{array}$ & Land retirement & EPIC \\
\hline $\begin{array}{l}\text { Kurkalova, } \\
\text { Kling \& Zhao } \\
2006\end{array}$ & lowa & $\begin{array}{l}\text { Corn and } \\
\text { soybean }\end{array}$ & Green subsidies & Conservation tillage & $\begin{array}{l}\text { Maximum } \\
\text { Likelihood } \\
\text { Estimation }\end{array}$ \\
\hline $\begin{array}{l}\text { Antle et al. } \\
2007\end{array}$ & lowa & $\begin{array}{l}\text { Corn-soy- } \\
\text { feed system }\end{array}$ & $\begin{array}{l}20 \text { year per-tonne } \\
\text { contract in which } \\
\text { areas are sampled } 4 \\
\text { times }\end{array}$ & Conservation tillage & Century \\
\hline $\begin{array}{l}\text { Singer, } \\
\text { Nusser \& Alf } \\
2007\end{array}$ & $\begin{array}{l}\text { Corn Belt } \\
\text { (USA) }\end{array}$ & $\begin{array}{l}\text { Wheat, } \\
\text { corn, } \\
\text { soybean, } \\
\text { and cash } \\
\text { grains }\end{array}$ & $\begin{array}{l}\text { Government } \\
\text { conservation } \\
\text { programs }\end{array}$ & Cover crops & Mailed Survey \\
\hline
\end{tabular}


The different studies from Table 1 provide important insights about carbon offset programs that are worth pointing out. Pautsch et al. (2000) estimate that the payments associated with a price discrimination subsidy could be up to 4.1 times lower than a single price subsidy. Mooney et al. (2002) use their study to verify that measuring and monitoring costs per carbon credit are inversely related to the price per credit. The Antle et al. (2003) study suggests the existence of a negative relation between payment levels and spatial heterogeneity as well as between relative efficiency of per-hectare contracts and spatial heterogeneity. They estimate that per hectare contracts could be as much as five times more costly than per-tonne contracts for the same agroecozone. Antle et al. (2007) realize that their aggregate econometric-process model produces a supply curve that is more elastic at low carbon prices.

Feng et al. (2005) conclude that there is a high degree of correlation between benefits and costs. In other words, areas with high cost shares generally have high benefit shares. Their empirical results further suggest that co-benefits are likely to be sizeable in absolute magnitudes in the UMRB (Upper Mississippi River Basin). Singer, Nusser and Alf (2007) estimate that around $55.7 \%$ of farmers are willing to use cover crops as long as they are offered cost-sharing options and a minimum payment of $\$ 23.20 \mathrm{ac}^{-1}$ on average. Kurkalova, Kling \& Zhao (2006) conclude that in order to induce the adoption of a conversation practice, the government could offer subsidies that overcome the adoption premium net of the expected gain from adoption. Furthermore, they observe that a substantial portion of the subsidy becomes income transfers to existing and low-cost adopters. Lastly, Kurkalova, Kling and Zhao (2004b) evaluate different measurement technologies under four institutional settings, which consist of the possible combinations between the cost discrimination or the lack of it and the payment for new benefits or the payment for all benefits. They conclude that if the cost of savings associated with the policy is high, investing in the development of improved technologies is then socially worthwhile. From these insights, it is clear that policy makers benefit from empirical studies and therefore should promote and support similar studies. 


\subsection{The Design of Carbon Offset Program from Agriculture}

A critical role for policy makers is to design carbon contracts. In the literature, there are at least four distinct approaches for designing carbon contracts: a per-tonne contract approach, an outputbased-offset (OBO) approach, a principal-agent contract approach, and a dynamic abatement cost model approach. Each approach is discussed next.

\subsubsection{Per-tonne Contract}

Antle et al. (2003) and Mooney et al. (2002) suggest the usage of per-tonne contracts over perhectare contracts. A per-hectare contract pays the same amount per hectare for all land that is converted to a specific conservation practice that is under the contract. In contrast, a per-tonne contract pays a specific price for each tonne of carbon that is sequestered and maintained in the soil while the contract lasts. Thus, a per-tonne contract does not specify the conservation practice the farmer adopts, since this freedom allows the farmer to choose the most efficient production practice at each specific location.

Both Antle et al. (2003) and Mooney et al. (2002) agree that per-tonne contracts are more efficient than per-hectare contracts. An important feature of per-tonne contracts is that they induce carbon to be sequestered up to the point where marginal cost per tonne equals market price per tonne. Differently, per-hectare contracts make farmers adopt a management practice without directly considering the amount of carbon sequestered (Mooney et al. 2002). A major question that arises is whether additional monitoring and measuring costs could offset the efficiency gains of per-tonne contracts. Antle et al. approach this question by proposing a useful measure of relative efficiency of contracts defined as the ratio of the marginal cost per-tonne contract and the marginal cost of perhectare contract (2003). Using this measure, their study shows that the marginal costs per tonne of sequestered carbon under a per-hectare contract could be as five times higher than under a per-tonne 
contract. This result suggests that contracting parties could potentially withstand measuring costs of per-tonne contracts and still attain a lower cost compared to a per-hectare contract.

Mooney et al. arrive at a similar conclusion in which additional measuring and monitoring costs are unlikely to make per-tonne contracts less efficient as long as the opportunity costs of supplying carbon credits are very different under both contract schemes (2002). Consequently, measuring and monitoring costs do not seem to offset the efficiency gains of a per-tonne contract, which suggests that policy makers should employ this per-tonne contract schemes over per-hectare contract schemes when designing carbon offset programs.

\subsubsection{An Output-based Offset (OBO) Approach}

Murray and Backer (2011) contrast the usage of output-based offset (OBO) approach over an area-based offset $(A B O)$ approach when designing a carbon offset program. An ABO approach is focused on absolute GHG reductions that are determined per hectare under the specific conservation practice. This approach establishes the baseline emissions and compares it to the expected emissions profile. The expected offset credit is then calculated as the difference between these two measures.

The OBO approach takes a further step and establishes a baseline for yields and emissions. The OBO approach establishes projected emissions and projected yields to calculate the baseline emissions intensity, defined as the ratio between projected emissions and projected yields. A farmer who enters a contract agrees to reduce emissions intensity, which is attainable either by reducing net emissions or increasing yields. Credits are calculated as the product of actual yield and the realized difference in intensities.

An advantage of the OBO approach is the inclusion of the way onsite yield changes influence production and emissions elsewhere. Assuming a fixed aggregate consumption demand for an 
agricultural commodity, an improvement in onsite yield could imply less cultivated area needed elsewhere. As cultivated area decreases, offsite emissions decline and could be credited in the contract. Some concerns about the OBO approach is that it only captures potential supply shifts under a fixed quantity demanded, which might not be very realistic. Ideally, the contract should capture both supply and demand responses. Moreover, including an intensity-based offset system to a program targeting absolute emission reductions could be problematic as the $\mathrm{OBO}$ approach focuses on decreasing emissions intensity and not necessarily reducing total emissions. Another concern stems from credits being functions of realized yields instead of expected yields, which adds an additional source of volatility to a measurement of offset effectiveness that is already volatile as it is. A possible solution is the establishment of insurance mechanisms for farmers who fail to reach GHG threshold due to unexpected yield losses. Murray and Backer (2011) conclude that an intensity-based approach could be more effective as a transitional strategy to address emissions from agriculture, but in the long term, policies should focused on absolute levels of emissions.

\subsubsection{Principal-Agent Contract}

Mason and Plantinga use a principal agent framework for carbon offsets contracts to respond to the problem of additionality $(2011)^{4}$. Policy makers who design offset programs are faced with the fact that there might be unidentifiable agents who could supply carbon offsets without any payment; thus, they wish to avoid including those agents in paying for and crediting offsets as they do not represent represent "additional" carbon gains. They focus on carbon offsets from forestation to illustrate their approach. The principal's objective is to maximize expected net benefits from forestation. Each contract has two elements: a per-unit payment or subsidy and a lump-sum transfer from the agent to the government. An agent's type is defined by the amount of land the agent would place in forest in the

\footnotetext{
${ }^{4}$ The problem of additionality is further discussed in Section 2.4.2
} 
absence of any government subsidy. The principal is unable to observe individual types, but he knows the distribution of the types. An agent could guarantee a positive payoff by pretending to be a lower type. An incentive compatible contract induces truth telling from the agent. Using a national-level simulation of carbon sequestration contracts, Mason and Plantinga conclude that principal-agent contracts are a less costly strategy for promoting the expansion or maintenance of forests compared to a constant per-unit subsidy (2011). Government costs are significantly lower under an optimal contract compared to a uniform subsidy. Even though this analysis assumes government purchases offsets, this approach could easily be extended to contracts in which private agents purchase offsets.

\subsubsection{Dynamic Stochastic Abatement Cost Model}

Fell et al. suggest the usage of a dynamic stochastic abatement cost model for policy design when there are correlated uncertainties in offset supply and abatement costs (2010). Their model is parameterized with reference to the recently proposed federal cap-and-trade legislation H.R 2454. A dynamic approach seems appropriate since the proposed legislation allows for permit banking and some form of limiting borrowing, which transforms the static cost minimization problem into a dynamic problem.

They model offsets as a linear function of offset price. From the optimization process, the representative firm purchases offsets until the marginal cost of abatement equals twice the offset price, which is a result that also appears under a monopsonistic behavior. The Euler equation states that the marginal cost of abatement increases at the expected rate of interest except for periods in which the bank constraint binds. They further suggest the usage of a price collar to face the added uncertainty from offsets. In particular, a price collar imposes a price floor and a price ceiling on the emission allowance prices in a cap-and-trade system. They compare their estimates to the Energy Information 
Administration's (EIA's) estimates, concluding that the supply slope for each year at the offset price is half of the EIA's expected emission price for the corresponding year (Fell et al. 2010).

Besides these four approaches for designing carbon offset policies, there are several papers that list specific steps for implementing offset program (See Gramig 2010, Antle et al. 2003, Hahn \& Richards 2010, Mooney et al. 2002, Murray \& Backer 2011 and Paustian et al. 2001). Table 1 summarizes some empirical studies on carbon offset program from agriculture.

\subsection{Benefits of Carbon Offset Programs from Agriculture}

In order to truly understand whether carbon offsets from agriculture should be included in environmental programs, policy makers must understand the benefits of the programs and potential issues that arise. In this section we identify the benefits of establishing carbon offsets programs from agriculture that a range of authors have described. Following this, potential issues and challenges that policy makers could face when designing and implementing carbon offset programs are discussed. For instance, carbon offset programs reduce compliance costs and provide time to develop better technologies to adapt to a new low-carbon economy (Murray \& Jenkins 2010). On a related theme, as better technology is developed, future emission costs could decrease (Paustian et al. 2001).

\subsubsection{Co-benefits and Complementary Relationships}

Other authors have pointed out that, in order to truly comprehend the potential impacts of carbon offset programs from agriculture, policy makers must consider co-benefits and complementary relationships that arise from the programs. To begin with, there are several co-benefits that are related to environmental goods. Kurkalova, Kling \& Zhao (2004a) study environmental benefits from conservation tillage in lowa. They focus on four performance-based benefits: carbon sequestration, reduction in nitrogen runoff, reduction of soil erosion by wind, and reduction of soil erosion by water. 
They contrast a practice-based policy and a performance-based policy. The latter pays for the adoption of a practice, but it targets farmers that can provide the highest amount of benefit per dollar spent. They find that targeting carbon leads to the reduction in nitrogen runoff, wind erosion, and water erosion compared to a practice-based targeting. In addition, targeting a single environmental benefit results in higher percentages of the other three benefits compared to the case in which they all are targeted directly.

Besides environmental co-benefits, several authors have identified other types of co-benefits. Feng et al. identify two co-benefits: an income support co-benefit and a pricing co-benefit (2005). The first is defined as the additional amount obtained by the farmer after receiving the full opportunity cost of a new practice. The latter is defined as the benefits for farmers that arise from having higher agricultural commodities prices. They perform a study in the Upper Mississippi River Basin (UMRB) and conclude that the distribution of benefits is very uneven across geographical areas. They also observe that targeting benefits generally enrolls more land than targeting area and that co-benefits are likely to be sizable in absolute magnitudes in the UMRB (Feng et al. 2005).

Similarly, McCarl and Schneider explore co-benefits from agriculture and forestation (AF) carbon programs (2001). They observe that the interdependence between AF-based environmental impacts calls for a combined conservation policy, which could be more efficient than focusing on environmental goals separately. Elbakidze and McCarl study a specific example in which a power plant can purchase sequestration-based agricultural permits to avoid reducing its own emissions (2004). As the plant is able to purchase permits, its emissions could actually increase. Empirical work suggests that increased power plant activity generates additional environmental co-costs. After estimating the co-costs and cobenefits, they conclude that agriculture co-benefits could potentially be offset by nonagricultural costs. From these examples, it is clear that considering co-benefits and co-costs is important when designing 
programs. However, measuring these co-effects and comparing them is a difficult task since they are highly dependent on the specific situation and its characteristics (Elbakidze \& McCarl 2004).

\subsubsection{Double Dipping and Welfare Analysis}

Woodward explores possible benefits from allowing double dipping in offset programs in a first best and second best economy (Woodward \& Han2004; Woodward 2011). Double dipping exists when providers of environmental credits are able to sell credits in multiple markets (Woodward 2011) associated with the same adoption of a conservation practice. An example might be the ability of a farmer to sell carbon credits from the adoption of no-till in both a carbon market and a water quality trading program. As double dipping is allowed, returns on credits increase encouraging more farmers to join those credit programs, which ultimately benefits the environment. In a first best economy, double dipping is efficient as long as aggregate caps are set optimally, meaning that they are set where the marginal benefit from the joint production of pollutant equals the marginal cost. Note, typically, the levels are set where marginal benefit equals marginal cost pollutant by pollutant, ignoring joint effects and interactions between pollutants.

In a second best economy, polluters can emit two pollutants. The regulation of one pollutant brings abatement on the other pollutant and caps are set pollutant by pollutant. However, note that ideally, the true social marginal cost must include the free abatement from the second pollutant. Since the cap level is not set optimally (i.e. ignoring abatement of second pollutant), welfare loss emerges. The assessment of double dipping's social loss is based on the slopes of the marginal cost and marginal benefit curves. If the marginal benefit is steep, then it is more efficient to prohibit double dipping. If the marginal benefit is flatter, then double dipping is more efficient (Woodward \& Han 2004). As the MC curve becomes flatter, double dipping becomes the less expensive way to achieve a level of abatement (Woodward 2011). 
Besides Woodward, other authors explore welfare implications of carbon offset programs from agriculture. Murray and Jenkins (2010) point out that when either additionality or leakage is ignored, a deadweight loss to society emerges. Hahn and Richards argue that it is possible that the costs to society are higher than the benefits from an offset program. In fact, they claim that offsets are usually an inefficient way of providing subsidies for particular kinds of energy sources (2010). In the following section, issues that arise when designing carbon offset programs are discussed.

\subsection{Issues to be Addressed in Offset Design}

The uncertainty that surrounds the design of carbon offset programs raises several challenging issues that must be addressed before an efficient program can be developed. These issues include additionality, leakage, permanence, measuring and monitoring costs, and distributional effects. This section explores these issues and discusses possible solutions in turn.

\subsubsection{Additionality}

A major issue that arises when designing carbon offset programs from agriculture is additionality (Garmig 2010). Mason and Plantinga characterize carbon offsets as impure public goods, in which there are some unidentifiable agents who could supply the public good without any payment (2011). The government should design a carbon offset program in such a way that it avoids payments for non-additional offsets. Otherwise, substantial costs could be associated with the purchase of offsets that are not generating any real environmental benefit. Policy makers face the challenge of distinguishing which offsets are in fact additional, since many farmers might be willing to adopt a specific conservation practice in the absence of a carbon offset program.

The problem of additionality is closely related to the establishment of the baseline beyond which offsets are earned. Baselines cannot be directly observed since they are the amount of emissions in the absence of an offset system (Bushnell 2010) and are therefore subject to uncertainty. Aldy et al. 
discuss the importance of setting the baseline correctly when designing carbon offset program (2009). Moreover, Fell et al. discuss uncertainty in baseline emissions and uncertainty in offset supply. Due to the correlation between emission levels and economic activities, shocks to the baseline emissions are assumed as temporally correlated and are modeled through an AR(1) process (2009). They propose the usage of a price collar in their dynamic stochastic cost model to face the uncertainty from baseline emissions and from offset supply. The implementation and implications of using a price collar were discussed under Section 2.2.4.

Bushnell explores the implications of moral hazard and adverse selection in carbon offset programs (2010). The latter occurs when the government ends up paying too much to farmers with already low emissions. The former occurs when farmers actively try to inflate their baseline. Bushnell claims that adverse selection is strongly linked to the distribution of "errors" in the forecast of BAU emissions. Specifically, if the errors are assumed to be independently distributed, offsets can produce under-abatement. Alternatively, if the errors are assumed to be highly correlated, aggregate baseline information is revealed He proposes the usage of randomized trials as a tool to address adverse selection and moral hazard (Bushnell 2010).

Hahn and Richards discuss concerns about adverse selection, moral hazard and information asymmetries and propose possible solutions as well (2010). For moral hazard and adverse selection, the offset program could provide sufficient property rights to all offsetting parties. For information asymmetries, the program could gather better information to determine the baseline. It could also limit the eligibility for trading offsets (Hahn \& Richards 2010). Mason and Plantinga notice the presence of information asymmetries between the principal and the agents and use an incentive compatible principal-agent dynamic contract to solve this problem (2011). 
Murray and Jenkins approach the problem of additionality by contrasting a perfect offset program with an imperfect offset program (2010). They define a perfect offset program to be one in which the offset function represents true marginal abatement cost from the uncapped sector. An imperfect offset program is one that contains additionality and leakage. They define additional reductions as those that are different from business as usual (BAU) reductions. Ignoring additionality could create a deadweight loss to society.

Murray and Jenkins take a further step and propose three policy approaches to correct welfare distortions from additionality (2010). First, they propose to eliminate BAU abatement from use as credit through the usage of additionality tests such as a financial assessment test determining which land use is more profitable. Alternatively, the program could enforce limit-entry criteria in which projects with low probabilities of being additional are denied entrance. They also suggest that setting a specific start date before the policy is introduced avoids strategic actions in anticipation of the policy. By removing the BAU abatement from offset credits, capped sectors are forced to compensate the reduction by having a higher abatement level that achieves the compliance cap. They conclude that BAU abatement should be eliminated from offset programs as long as this can be done in a costless manner.

The second approach is to accept the existence of all offsets (including non-additional offsets) but apply a discount factor to issued credits to take into account the likelihood that some of the offsets will in actually be non-additional. In this case, the regulator establishes a discount factor on all credits proportional to estimates of how many credits are likely to be non-additional (i.e. the regulator requires more than one unit of abatement for every issued credit). For example, suppose a regulator estimates that $20 \%$ of all offsets are non-additional. Then, the regulator requires that only $80 \%$ of any given offset can be bought or sold in the market. Overall, this approach can be expected to incur higher costs to reach an abatement target compared to the case in which the regulator can identify which offsets are 
indeed additional. By discounting, offset buyers experience a welfare loss and offset producer surplus increases compared to the case when all offsets are genuinely additional (Murray \& Jenkins 2010).

The last approach consists of addressing additionality indirectly by tightening the aggregate emissions cap. A regulator estimates the abatement lost due to additionality and then adjusts the cap to reflect this loss (i.e. if the estimation is large, the regulator can increase the cap accordingly). Continuing with the previous example, a regulator can raise the emissions cap $20 \%$ and give full credit for carbon sequestration. An increase in the cap shifts the demand for offsets out. This approach increases the total economy-wide obligation for offsets, but if the estimate of nonadditionality is correct, then the actual abatement achieved will just meet the target. In particular, capped sectors will have to do more abatement as well as seek more abatement from uncapped sectors through offsets. The intuition is simple: as the offsets supply curve does not change as producers are not affected directly, the shift in demand brings about more offsets.

To meet the target, Murray and Jenkins argue that there could be less uncertainty in meeting the target using this approach compared to the second approach. Requiring more abatement increases the demand for offsets only. More offsets are produced in response to higher prices driven by the demand increase, which increases the initial producer surplus. Under this approach, offset providers are the most benefited due to the increase in price and quantity of credits sold (Murray \& Jenkins 2010).

\subsubsection{Leakage}

A third challenge faced by policy makers is to take into account leakage when designing the carbon offset program (Aldy et al 2009). Leakage captures the idea that offset-driven carbon sequestration gains could be shifted to another uncapped source that increases emissions. Taking into account leakage is crucial for determining the offsetting validity of the program (Murray \& Jenkins 2010). 
Measuring leakage contains a high degree of uncertainty. As with additionality, Murray and Jenkins propose approaches to correct for welfare distortions caused by leakage. Their first approach suggests that policy makers could address leakage at a project level by enhancing monitoring systems and policy design. They could also address it by establishing "leakage belts" or by adjusting crediting at a project level. This project level approach is limited because it is unable to consider leakage that goes beyond a local area. Likewise, it is costly due to substantial transaction costs from monitoring leakage on a project-to-project basis. Their second strategy consists on discounting all credits to account for leakage using a similar approach as with additionality. Their third approach is based on broadening an offset program to include more uncapped sectors or by enlarging a regulatory cap to include uncapped activities (Murray \& Jenkins 2010). Alternatively, Murray and Backer claim that OBO could potentially eliminate the need for a leakage discounting and that $\mathrm{OBO}$ credits implicitly capture leakage effects in onsite crediting (2011). They focus on supply responses, but ignore demand response, which is a major limitation of their model. Leakage is certainly another major issue that policy makers must address when designing carbon offset programs.

\subsubsection{Permanence}

Carbon sequestering activities in agriculture are subject to the problem of nonpermanence. When carbon is built up in the soil via reduced tillage or other practice, there is the potential for it to be released if the practice is not continued. Thus, if reduced tillage is practiced for several years, but then the soil is tilled, much of the stored carbon will be released into the atmosphere, making the GHG reductions only temporary. For a biological description of this problem, refer to Sedjo and Sohgen's review in this volume as they clearly describe the biological process behind carbon sequestration. Paustian et al. discuss the concern about the permanence of carbon in the soil and further note that the soil has a limiting capacity to hold carbon (2001) so even if a practice like reduced tillage is continued, 
there is a maximum carrying capacity of the soil. They note that temporary storage has value due to discounting on the flow of carbon. From a stock pollutant perspective, temporary storage has value even without social discounting, since carbon decreases the stock for the period in which carbon is stored (Paustian et al. 2001).

The problem of permanence has received considerable discussion and authors have noted that contracts can be written to account for this problem. Feng, Zhao and Kling (2002) emphasize the need for government programs to properly account for the "net value" of temporary storage of carbon. They suggest three systems to implement the optimal sequestration levels: a pay-as-you-go (PAYG) system, a variable-length contract (VLC) system, and a carbon annuity account (CAA) system. Under a PAYG system, emission credits are sold and repurchased by farmers based on the permanent reduction of carbon. Alternatively, under a VLC system, private broker arrangements generate "permanent" carbon reductions that stem from separate temporary reductions. Lastly, under a CAA system, the amount of carbon sink is paid the full value of a permanent reduction as in the PAYG, but this payment is deposited into an annuity account instead of being given to the farmer as in the PAYG. These three systems attain the theoretically efficient solution.

Feng (2005) explores different carbon accounting methods to address the nonpermanence nature of carbon sinks. The three accounting methods she studies are: (1) annual average carbon, (2) annualized carbon, and (3) ton-year carbon. The annual average carbon is the sum of carbon sequestered over a specific period of time divided by the length of the period. The annualized carbon method discounts carbon sequestered in future periods. Lastly, the ton-year carbon accounting considers the duration of carbon kept away from the atmosphere. Feng (2005) concludes that the optimal accounting method tends to be study specific. 
Murray, Sohngen and Ross (2007) also address the problem of nonpermanence as farmers can switch back to a conventional practice and release some sequestered carbon back into the atmosphere. They propose three project credit adjustments to account for the nonpermanence of soil carbon sinks: (1) comprehensive accounting, (2) ex ante discounting accounting, and (3) temporary credit accounting. Comprehensive accounting is based on the balance between credits that are given as carbon is stored and debits that are given as carbon is released back into the atmosphere. This accounting method requires regular carbon stock measurements. Alternatively, the ex ante discounting method estimates the expected amount and timing of carbon release, which is accounted for at the beginning of the project when credits are assigned to the contract. Note that this method is based on the assumption that carbon will be released at a certain time, but there could be times in which carbon is not released into the atmosphere. Lastly, temporary credit accounting assigns finite life on debits and credits.

García-Oliva and Masera (2004) also stress the importance of considering the nonpermanence of carbon sinks when designing carbon offset programs. They propose ways to account for the reversibility of carbon sequestration. Specifically, they suggest that projects must demonstrate financial, legal and technical viability and capacity. They also stress the need for a clear definition of liability and a detailed risk management plan (i.e. insurance, credit reverses or buffers) to account for the nonpermanence of carbon in the soil. Overall, despite the concern about permanence, there is value for the temporary storage of carbon in the soil.

\subsubsection{Measuring and Monitoring Costs}

Following the discussion on per-tonne contracts under Section 2.2.1, concerns are raised about measuring and monitoring cost (Antle 2008; Antle et al. 2003). Paustian et al. emphasize the importance of measuring sequestration and emission rates in carbon offset programs, since GHG emissions are nonpoint source pollutants (2001). They suggest that monitoring programs could be based on aggregate 
pollution and observable individual actions. Antle et al. suggest to measure the amount of soil C sequestered by sampling and estimating the average $C$ accumulation of each practice in a relatively homogenous agroecozone (2003). Alternatively, Mooney et al. propose that in order to monitor that farmers are using an eligible practice, programs could use remote sensing, aerial photography or drive by inspection (2002).

\subsubsection{Distributional Effects}

Similar to the way carbon offset programs have co-benefits, they also have co-costs. Elbakidze and McCarl's empirical work on the power plant example discussed in Section 2.3.1 suggest that agricultural co-benefits could potentially be offset by nonagricultural co-costs (2004). Co-costs from carbon offset programs have distributional effects. For instance, carbon offset programs benefit farmers through the increase in prices, but this increase harms consumers (McCarl \& Schneider 2001). Murray and Jenkins realize that their three approaches to additionality have different distributional results. Offset suppliers are better off with the discounting approach as producer surplus is higher. They are even better off under the cap adjustment approach since it induces the highest producer surplus. At the same time, these gains make offset buyers in the capped sector worse off as they face larger payments (Murray \& Jenkins 2010). Thus, carbon offset programs could induce some distributional effects.

\section{Conclusion}

While climate change does not seem to be getting substantial attention in the current federal policy agenda of the United, the offset potential of agriculture is likely to play a significant role on the next farm bill and related conservation programs. Offsets are desirable for implementation when reductions to outside sources can be achieved less expensively than reductions to the covered sources, thereby decreasing the costs of program compliance. Before designing carbon offsets, policy makers need to understand the economic potential of carbon offsets from agriculture. Once the potential is estimated, 
supply curves are derived to determine the amount of carbon that is sequestered given a carbon price. Policy makers can use these supply curves to design carbon contracts. In this paper, we review four distinct approaches for designing carbon contracts: a per-tonne contract approach, an output-basedoffset (OBO) approach, a principal-agent contract approach, and a dynamic abatement cost model approach.

When designing carbon contracts, policy makers must consider co-benefits and complementary relationships that arise from the programs. Similarly, they must understand the challenges that are faced while designing offset programs. The uncertainty that surrounds the design of carbon offset programs raises several challenging issues that must be addressed before an efficient program can be developed. This review explores challenges and solutions for problems such as additionality, leakage, permanence, measuring and monitoring costs, and distributional effects. In the end, this review provides a comprehensive overview of carbon offsets from agriculture that includes the various elements that must be considered when designing an efficient carbon offset program.

\section{Bibliography}

Aldy J,Krupnick A, Newell RG, Parry IWH, Pizzer WA. 2009. Designing Climate Mitigation Policy. Discussion Papers, May, Resources For The Future

Antle J. 2008. Is There a Role for Geologic and Terrestial Carbon Sequestration in Greenhouse Gas Mitigation? Discussion paper, Resource for the future

Antle J. 2009. Modeling the Costs and Volumes of GHG Offsets: Soil C Sequestration. REF/EPA GHG Offsets Workshop

Antle J, Capalbo S, Mooney S, Elliot E, Paustian K. 2003. Spatial Heterogeneity, contract design, and the efficiency of carbon sequestratino policies for agriculture. Journal of Environmental Economics and Management 46:231-250

Antle J, Capalbo SM, Paustian K,Ali MK. 2007. Estimating the economic potential for agricultural soil carbon sequestration in the Central United States using an agrregate econometric-process simulation model. Climatic Change 80:145-171. 
Bushnell J. 2010. The Economics of Carbon Offsets, NBER Working Paper.

EIA. 2009. Energy Market and Economic Impacts of H.R. 2454, the Amerian Clean Energy and Security Act of 2009, Energy Information Administration, Washington, DC.

Elbakidze L, McCarl B.2004. Should We Consider the Co-benefits of Agricultural GHG Offsets? Choices, Fall:25-26.

Fell H, Burtraw D, Morgenstern R, and Palmer K. 2010. Climate Policy Design with Correlated Uncertainties in Offset Supply and Abatement Cost. Discussion Paper RFF DP 10-01,Resources For The Future.

Feng H. 2005. The dynamics of carbon sequestration and alternative carbon accounting, with an application to the upper Mississippi River Basin. Ecological Economics 54: 23-35.

Feng, H, Kurkalova LA, Kling CL and Gassman PW. 2005. Economic and Environmental Co-benefits of Carbon Sequestration in Agricultural Soils: Retiring Agricultural Land in the Upper Mississippi River Basin. Climate Change, DOI 10.1007/s10584-006-9143-1

Feng H, Zhao J, Kling CL. 2002. The Time Path and Implementation of Carbon Sequestration. American Journal of Agricultural Economics 84(1):134-149.

García-Oliva F, Masera OR. 2004. Assessment and Measurement Issues Related to Soil Carbon Sequestration in Land-use Change, and Forestry (LULUCF) Projects Under The Kyoto Protocol. Climatic Change 65:347-364.

Gramig BM. 2010. Greenhouse Gas Emissions Offsets from Agriculture: Opportunities and Challenges, Purdue Agricultural Economic Report http://www.agecon.purdue.edu/extension/pubs/paer/2010/february/gramig.asp

Grubb M, Laing T, Counsell T, Willan C. 2011. Global carbon mechanisms: lessons and implications. Climatic Change 539-573.

Hahn, R W. Richards KR. 2010. Environmental Offset Programs: Survey and Synthesis. Indiana University School of Public \& Environmental Affairs Research Paper No. 2010-12-01, http://ssrn.com/abstract=1721544

Kurkalova LA, Kling CL, Zhao J. 2004 (a). Multiple Benefits of Carbon-Friendly Agricultural Practices: Empirical Assessment for Conservation Tillage in lowa. Environmental Management 33:519-527.

Kurkalova LA, Kling CL, Zhao J. 2004 (b). Value of Agricultural Nonpoint Source Pollution Measurement Technology: Assessment from a Policy Perspective. Applied Economics 36:2287-2298.

Kurkalova LA, Kling CL, Zhao J. 2006. Green Subsidies in Agriculture: Estimating the Adoption Costs of Conservation Tillage from Observed Behavior. Canadian Journal of Agricultural Economics. 247267. 
Lecocq F, Ambrosi P. 2007. The Clean Development Mechanism: History, Status, and Prospects. Review of Environmental Economics and Policy. 1(1):134-151.

Mason CF, Plantinga A J.2011. Contracting for Impure Public Goods: Carbon Offsets and Additionality. Work. Pap.,564,Fondazione Eni Enrico Mattei. http://www.bepress.com/feem/paper564

McCarl B, Schneider U. 2001. Greenhouse Gas Mitigation in U.S. Agriculture and Forestry. Science 294(5551):2481-82.

Mooney S, Antle J, Capalbo S, Paustian K. 2002. Contracting for Soil Carbon Credits: Design and Costs of Offsets. Presented at American Agricultural Economics Association Annual Meeting, Long Beach

Murray BC, Baker JS. 2011. An output-based intensity approach for crediting greenhouse gas mitigation in agriculture: explanatin and policy implications. Greenhouse Gas Measurment and Management 1:27-36.

Murray BC, Jenkins WA. 2010. Designing Cap and Trade to Account for "Imperfect" Offsets. Duke Environmental Economics Working Paper Series, September.

Murray BC, Sohngen B, Ross MT. 2007. Economic consequences of consideration of permanence, leakage and additionality for soil carbon sequestration projects. Climatic Change. 80:127-143.

Paustian K, Antle M, Sheehan J, Eldor P. 2006. Agriculture's Role in Greenhouse Gas Mitigation. Pew Center on Global Climate Change

Paustian K., Babcock B, Kling C, Hatfield J, Lal R, Mccarl B, Post WM, Mosier A., Rice R, Robertson GP. 2001. Agricultural mitigation of Greenhouse gases: science and policy options. Presented at National Conference on Carbon Sequestration

Pautsch GR, Kurkalova LA, Babcock BA, Kling CL. 2000. The Efficiency of Sequestering Carbon in Agricultural Soils. Contemporary Economic Policy 19:123-134

Sedjo R, Sohngen, B. 2012. Carbon Sequestration in Forests and Soils. Annual Review of Resource Economics 4 (current issue).

Singer J, Nusser S, Alf C. 2007. Are cover crops being used in the US corn belt?. Journal of Soil and Water Conservation. 62:353-358

Smith P. et al. 2008. Greenhouse gas mitigation in agriculture. Philosophical Transactions of The Royal Society-Biological Sciences. 789-814

Woodward R, Han M. 2004. Double Dipping in Pollution Markets. Presented at Annu. Meet.Am. Agricultural Economics Assoc., Denver

Woodward RT.2011. Double Dipping in Environmental Markets. Journal of Environmental Economics and Management. 61:153-169. 
lowa State University does not discriminate on the basis of race, color, age, religion, national origin, sexual orientation, gender identity, genetic information, sex, marital status, disability, or status as a U.S. veteran. Inquiries can be directed to the Director of Equal Opportunity and Compliance, 3280 Beardshear Hall, (515) 294-7612. 